\title{
Política y postmodernidad (Lyotard, Popper, Luhmann y Habermas)*
}

La "política" y la "postmodernidad" apuntan a realidades apasionantes y polémicas. Se puede hablar hasta la saciedad de la una y de la otra - se ha hablado ya bastante de ambas - sin que se agote nunca el afán por entenderlas. ¿De qué se trata cuando hablamos de política? ¿De qué se trata cuando hablamos de postmodernidad? A continuación voy a tratar de responder muy sencillamente a estas interrogantes.

Política. En la actualidad, cuando hablamos de "política" hablamos de dos cosas en lo fundamental. En primer lugar, hablamos de un ejercicio intelectual que, desde Aristóteles hasta los autores contemporáneos - pienso en Giovanni Sartori y Robert Dahl-, ha cristalizado en las diversas teorías políticas que ha conocido la humanidad. Aquí la política es pensamiento político: elaboración conceptual que se ocupa de cuatro cuestiones fundamentales: (a) quién o quiénes dirigen la sociedad; (b) cuál es la naturaleza de su mandato (su fuente de autoridad); (c) cuáles son los mecanismos a partir de los cuales se decide ese mandato; y (c) de qué naturaleza son las relaciones entre gobernantes y gobernados.

Por supuesto, el pensamiento político se ocupa de otras muchas cuestiones; asimismo, los argumentos y perspectivas varían de autor a autor, al igual que son variadas las condiciones históricas y sociales en las cuales cada pensador realiza $-y$ ha realizado en el pasado-- su reflexión política. Pero los cuatro aspectos anteriores pueden ser rastreados en cualquiera de los grandes pensadores de la política del pasado o del presente.

La política es, pues, en un sentido pensamiento político. Sin embargo, la política tiene también otro sentido: es una actitud vital o, mejor aún, un ejercicio cotidiano. ¿A qué apunta la política como actitud vital? Ante todo, a la convivencia social a la cual todos los seres humanos nos vemos abocados. Es ineludible convivir con otros, no sólo con los que se tienen relaciones horizontales, sino con quienes gobiernan desde las esferas del poder estatal. Esta convivencia es política en acto; es ejercicio político.

Pero la política en este segundo sentido que nos ocupa es más que el mero convivir con otros en sociedad. Se trata de convivir de determinada manera: se trata de convivir como ciudadanos. Y la ciudadanía apunta básicamente al respeto de los derechos de los otros en cuanto distintos; también apunta al reconocimiento, aceptación y defensa de los propios derechos y deberes; y, finalmente, apunta a la responsabilidad de cada uno ante los problemas que afectan al conjunto de la sociedad.

* Texto de la charla ofrecida al curso de formación en teoría política "Bases histórico-filosóficas del pensamiento político", coordinado por Ernesto Wathion, del Departamento de Filosofía de la UCA, y ofrecido durante los meses de enero y febrero de 1998. 
No se puede ser plenamente un "animal político" sin ejercitar cotidianamente las virtudes que son propias del comportamiento político.

Entonces, cuando se habla de política, se habla de dos cosas formalmente distintas: se alude a la política como ejercicio intelectual (que se expresa en las diversas teorías políticas) o se alude a la política como ejercicio vital, como ejercicio cotidiano de las virtudes políticas. Entre ambas existe una diferencia importante: como ejercicio intelectual, la política es realizada por especialistas; como ejercicio cotidiano, la política es realizada por todos aquellos grupo sociales -de los cuales son parte los teóricos de la política- que han adquirido la madurez ciudadana necesaria.

Postmodernidad. Cuando se habla de "postmodernidad" se habla de dos cosas: en primer lugar, de un pensamiento postmoderno; $y$, en segundo lugar, de un conjunto de actitudes motivadas por lo que se ha dado en llamar el "clima cultural" de la postmodernidad. Como reflexión intelectual, el pensamiento postmoderno quiere dar cuenta del agotamiento y crisis del proyecto de la modernidad. Quiere dar cuenta de las raíces culturales, filosóficas, políticas y económicas de la modernidad, así como de la lógica perversa que las alimenta; desde ese diagnóstico, el pensamiento postmoderno vislumbra el advenimiento de una nueva época histórica, la irrupción de un tiempo nuevo, en el que predomina lo fragmentario sobre lo unitario; lo local y particular sobre lo total; la sensibilidad sobre la racionalidad; los compromisos efímeros sobre los propósitos universales.

Todos los que dedican atención a esta nueva época histórica (Lyotard, Foucault, Vattimo, Rorty, Berman), así como a los elementos que la caracterizan cultivan un pensamiento postmoderno, que como tal es competencia de un grupo bastante reducido de especialistas que desde finales de los sesenta comenzaron a diagnosticar los "males de la modernidad". Pero la postmodernidad, ya lo dijimos, alude también a una serie de actitudes $y$ comportamientos motivados por el "clima cultural postmoderno". Este clima cultural es propiciado, ante todo, por los diversos experimentalismos estéticos (literatura, poesía, cine, pintura) que acentúan, incluso hasta el extremo, valores y opciones hedonistas.
También ese clima cultural es propiciado por la saturación del espacio de las comunicaciones, lo cual no sólo impide hacerse una idea de conjunto de lo que sucede en el mundo, sino que hace que todo aparezca - aun los hechos más brutalescomo algo efímero y evanescente.

Así, los valores postmodernos, al propagarse por la sociedad, son asumidos por grupos sociales cada vez más amplios, entre los cuales la juventud ocupa un lugar destacado -y también algunos de los pensadores postmodernos.

¿Cuáles son los rasgos más notables de la postmodernidad como estilo de vida? (a) Predominio de la sensibilidad y aceptación de todo aquello que la estimule; (b) fuertes compromisos con grupos particulares de interés; (c) ausencia de compromisos macrosociales de largo plazo; (d) aceptación de la horizontalidad en las relaciones interpersonales; (e) rechazo de las jerarquías tradicionales de la sociedad; (f) rechazo de los estilos de vida (modas, costumbres, tradiciones) considerados como socialmente normales; y (g) aceptación de la desarmonía y lo absurdo.

En fin, aunque desde hace varios años el pensamiento postmoderno no da lugar a contribuciones en verdad trascendentales, como estilo de vida, el postmodernismo se expande cada vez más en los diversos rincones del planeta. Y todos, en mayor o menor medida, asumimos de vez en cuando actitudes postmodernas.

Postmodernidad y política. Aquí me voy a detener en un aspecto: ¿cuáles son las relaciones existentes entre la postmodernidad como estilo de vida y la política como actitud vital? Pues bien, la 
actitud postmoderna, llevada al límite, tiende a socavar las virtudes políticas más profundas, como lo son la responsabilidad social y el compromiso con proyectos que apuntan al bien común.

Existe, por supuesto, un punto de coincidencia: a la política como actitud vital le es consustancial el respeto a $-\mathrm{y}$ el reconocimiento de- los otros en tanto que distintos. El estilo de vida postmoderno reivindica lo distinto y diverso como algo que está por encima de lo unitario y lo homogéneo. Sin embargo, más de allá de este acercamiento que se explica porque al fin y al cabo el estilo de vida postmoderno se nutre, lo quiera o no, de actitudes afincadas en la modernidad-, un estilo de vida postmoderno es contrario (por los valores en los que se funda) a un estilo de vida anclado en los valores políticos más hondos. Y ello porque, tal como esos valores han evolucionado hasta nosotros, son inseparables: (a) de una actitud razonable y racional ante los problemas sociales; (b) de un compromiso macrosocial de mediano y largo plazo; (c) de una aceptación de las jerarquías sociales; y (d) de una aceptación del orden como preferible al caos y a lo absurdo.

\section{Algunos autores: Lyotard, Popper, Luhmann y Habermas}

De entrada, puede sorprender ver juntos a esos cuatro autores. Cada uno ha contribuido con su respectivo aporte al debate sociocultural de los últimos veinte o treinta años. Pero, ¿cómo entender en una rápida mirada sus aportes? Con Habermas y Luhmann la operación es bastante sencilla, puesto que ambos son interlocutores desde hace un buen tiempo. Entre Lyotard y Popper, al menos inicialmente, no son tan claros los puntos de encuentro o desencuentro; pero los hay. A continuación veremos muy brevemente en qué consisten los encuentros o desencuentros entre, por un lado, Habermas y Luhmann y, por el otro, entre Popper y Lyotard. Sin olvidar, claro está, el tema que nos ocupa: la postmodernidad y la política.

\section{Lyotard y Popper}

J. F. Lyotard, digámoslo de una vez, es un pensador postmoderno. Entre sus libros más conocidos están La condición postmoderna y La postmodernidad (explicada a los niños). Como pensador postmoderno, Lyotard se ocupa, ante todo, de la ruptura que supone para la tradición ilustrada el pluralismo de los juegos de lenguaje al que asistimos en la época actual. La pluralidad de los juegos del lenguaje no sólo impone a los seres humanos el disenso, la diferencia, las discontinuidades y las paradojas, sino que fundamenta estilos de vida plurales y diversos.

Justamente a partir de aquí arranca la crítica de Lyotard y de otros pensadores postmodernos a los metadiscursos omniabarcadores con pretensión de fundamentación última. Para Lyotard, el saber postmoderno se separa del saber moderno en el momento en que renuncia sin desencanto a los "metadiscursos legitimadores".

$Y$, una vez instalados en la renuncia a los metadiscursos totalizantes, los valores y las opciones universales ceden su puesto a los criterios de validez de carácter local y contextual. Es decir, nos instalamos en un "politeísmo de los valores". El control, el poder y la regulación del sistema son una amenaza permanente para los individuos. El sistema se vale de las "narrativas de emancipación" que legitiman el terror que le es intrínseco; de lo que se trata es de ponerse a salvo de ese terror. La trinchera que protege a los humanos es lo estético-sensual, esa dimensión del individuo que lo resguarda de las amenazas dominadoras de la razón.

La pregunta que queda en pie es la siguiente: desde su particular perspectiva, ¿cuál es la postura de Lyotard ante la política (como saber y como actitud vital)? Como saber, la política es para Lyotard una de las expresiones de la razón dominadora; es un discurso que, en cuanto pretende explicar la naturaleza del poder de los gobernantes y el carácter de las relaciones entre éstos y los gobernados, termina legitimando la sujeción de unos hombres por otros.

Como actitud vital, la política es para Lyotard un estilo de vida que no tiene cabida en la condición postmoderna. En esta, están excluidos los compromisos de largo plazo fundados en responsabilidades compartidas, cuya mira sea el bien común. Todo lo contrario a lo que exigen las virtudes políticas.

K. Popper es, en muchos aspectos, lo opuesto de Lyotard. Valoró, por sobre todas las cosas, la Ilustración y el legado más importante de ésta: la ciencia moderna. A Popper no le interesó especialmente el debate postmoderno. Su interés como intelectual se decantó hacia la epistemología y la metodología; en concreto, hacia el modo cómo 
proceden los científicos en su búsqueda incesante de la verdad. Su esquema clásico es conocido por todos: problema-hipótesis-falsación de la hipótesis.

Pero detrás de ese esquema está una apuesta, reconocida una y otra vez por Popper, por la razón y su capacidad de acercamos cada vez más, en una búsqueda interminable, a la verdad de la realidad. La ciencia y la técnica son, a juicio del Popper espistemólogo, dos de los mejores logros de la modernidad. Por ellas y a través de ellas, hemos enriquecido nuestro conocimiento del mundo y lo seguiremos enriqueciendo en el futuro. Para el Popper ciudadano, la modernidad, tras largos y penosos esfuerzos de las generaciones pasadas, ha erigido a la libertad como uno de los pilares fundamentales de la humanidad. Una libertad que, indudablemente, se funda en la razón, de la cual se nutre, pero de la cual, a su vez, se convierte en protectora.

De este modo, la política para Popper es, como actividad intelectual, una manifestación más de ese esfuerzo humano por alcanzar un conocimiento racional del mundo, en este caso del mundo sociopolítico. Como actitud vital, expresa la ineludible responsabilidad de los seres humanos para construir un mundo mejor. Y vivir en un mundo mejor exige compromisos universales que en lo absoluto atentan contra la felicidad humana.

Popper y Lyotard: dos pensadores distintos, con dos opciones vitales distintas.

\section{Luhmann y Habermas}

Niklas Luhmann no es un pensador postmoderno, aunque sus aportes teóricos constituyen una crítica y una renuncia a algunos de los valores más queridos de la Ilustración. De hecho, Luhmann pretende superar la Ilustración en un aspecto específico: la primacía que ésta olorga al sujeto. En efecto, Luhmann pone entre paréntesis a la subjetividad humana en su estudio del sistema social. El individuo como sujeto queda fuera de las consideraciones lumanianas a la hora de explicar a la sociedad: los sujetos son parte del entorno de la sociedad. Esta, como sistema, se autorreproduce en y por sí misma, sirviéndose de los elementos existentes en su entorno - la naturaleza, los individuos-, con los cuales está en permanente pugna.

En Luhmann todo se explica, pues, por la relación sistema-entorno; justamente todo lo que no es sistema es entorno y viceversa. ¿Qué es un sistema? Todo aquello que posee capacidad de auto- poiesis, esto es, capacidad de autorreproducirse y autoconservarse sirviéndose de los recursos del entorno. ¿Cuál es el sistema más complejo? El sistema social, y su complejidad se ve confirmada por el hecho de que es un sistema capaz de observarse a sí mismo. ¿A través de qué? A través de la teoría social.

Y la política, ¿qué es para Luhmann? Es, ante todo, un subsistema del sistema social; un subsistema que le es funcional en la medida en que hace creer a los individuos que participan y deciden en la dinámica social. Pero esa participación y esa decisionalidad son una ficción, una ficción que, en tanto existe, dota al sistema social de legitimidad, evitando los conflictos y la inestabilidad. Hacer creer a los individuos que participan y deciden: esa es la función del subsistema político, del que son parte las teorías políticas, en las sociedades del capitalismo tardío.

En suma, en Luhmann hay una aceptación de una de las vetas de la modernidad: la que se nutre de las visiones totalizantes. También hay una valoración de la política, pero no de los valores IlusIrados que se le asocian a la misma - responsabilidad, compromiso-, sino de su funcionalidad sistémica.

J. Habermas se posiciona críticamente ante la modernidad y la ilustración, pero no para rechazar las energías subjetivas, sino para resarcirles su valor. En Habermas, el capitalismo tardío ha socavado la riqueza de la racionalidad humana al hacer predominar una de las dimensiones de la razón: la racionalidad instrumental. De lo que se trata, entonces, es de recuperar sus otras dos dimensiones: la relacional y la emancipadora.

Ahora bien, el restablecimiento de las dimensiones de la razón que han sido "colonizadas" por la razón instrumental no puede hacerse sin apelar a la propia racionalidad, una racionalidad que no está arrinconada en la conciencia individual, sino que es compartida intersubjetivamente, mediante el lenguaje, por los seres humanos. Entonces, la "liberación" de la razón es un acto comunicativo; es, también, un acto social. Asimismo, es el punto de partida ineludible para avanzar hacia otros procesos emancipatorios, como lo es la emancipación política.

Para Habermas, uno de los elementos de la crisis del capitalismo tardío consiste en haber reducido el papel de la política a hacer creer a los individuos que deciden y participan, cuando en verdad 
no lo hacen. Lo que está detrás de eso es el predomino de la racionalidad instrumental en la política. Lo político, por el contrario, es uno de los ámbitos de la realidad social; ese ámbito es en el cual los individuos pueden y deben encauzar sus energías ciudadanas en búsqueda de niveles más elevados de humanización.

En fin, Habermas se ha convertido en uno de los más fuertes críticos tanto de los que proponen una funcionalización de la política - a la manera de Luhmman - como de quienes promueven una huida de las responsabilidades públicas, so pretexto de que el único compromiso humanizador es el estético-sensible —como los postmodernos.

\section{Bibliografia}

González, L. A. "Modernidad y postmodernidad: reflexiones desde América Latina", Revista Realidad, No 44, marzo-abril, 1995.
González, L. A. "Teorfa crítica versus teorfa de sistemas: la confrontación Habermas-Luhmann", Revista Realidad, No 41, septiembre-octubre, 1994.

Habermas, J. "El fin de la utopía", Revista Realidad, No 45, mayo-junio, 1995.

Habermas, J. "La modernidad: un proyecto incompleto", AAVV, La postmodernidad, Kairos, 1985.

Habermas, J. La reconstrucción del materialismo histórico, Madrid, Taurus, 1992.

Luhmann, N. Sistemas sociales. Lineamientos para una teoría general, México, Universidad lberoamericana-Alianza editorial, 1991.

Lyotard, J.F. La postmodernidad (explicada a los niños), Barcelona, Gedisa, 1987.

Popper, K. En búsqueda de un mundo mejor, Barcelona, Paidós, 1994.

Vatimmo, G. (Comp.) La secularización de la filosofía. Hermenéurica y postmodernidad, Barcelona, Gedisa, 1992.

Luis Armando González 